a range of dementias, psychoses and emotional disorders. Group sessions aimed primarily at supporting the carers of elderly relatives appeared to be of some benefit.

The article by Drs Clausen and Wilson addresses a wider issue: the prospect of an ageing population in Africa. They point out that health budgets are severely limited for all African countries, and that priority is given to the needs of the younger generations, who are economically active. As the longevity of African adults increases in years to come, it is essential to maintain as high a proportion as possible of the ageing population in economic activity. This will entail a tradeoff between the cost of providing social and medical care, and the ability of that population to contribute to wealth generation. Currently, the provision of services to older patients with mental illnesses in most African countries is non-existent.
Finally, Professor Kua Ee Heok discusses the hidden burden of dementia among the elderly in South-East Asia. There is evidence that a very small proportion of all cases have been identified, and this is in part attributable to inadequate training of general practitioners. But even if identification were to be improved, would this lead to a higher priority being given to the care of elderly people with mental illness in the health services of that region? There is a change coming in the attitude of young people, who traditionally have cared for their extended families in multigenerational homes, such as the hutongs in Beijing. These young people want to live apart from their parents nowadays, in modern apartments, and community services have yet to compensate for that rapid change in cultural attitudes.

\title{
Group intervention for carers of geriatric patients: experiences from a clinic in India
}

\author{
J. Henry, ${ }^{1}$ A. Jagannathan, ${ }^{1}$ K. Bhavana, ${ }^{1}$ B. Thomas, ${ }^{1}$ S. Bharath, ${ }^{2}$ \\ M. Varghese, ${ }^{2}$ O. P. Jhirwal' ${ }^{2}$ and P. T. Sivakumar ${ }^{2}$
}

'Department of Psychiatric Social Work, National Institute of Mental Health and Neurosciences (NIMHANS), ${ }^{2}$ Department of Psychiatry, NIMHANS, Bangalore, India email srikala.bharath@gmail.com

\begin{abstract}
ixty per cent of the global elderly population live in lowand middle-income countries, and this proportion was expected to rise to $70 \%$ by 2010 (International Institute of Ageing, 2001; Ferri et al, 2005). The 2001 Indian census found over 70 million people aged 60 years or more (considered senior citizens according to the Indian National Policy on Older Persons). Most of those senior citizens live with younger family members and are dependent on them for financial and social support. Hence, any physiological and psychological changes in the older family members affect the younger supportive members as well.

According to the findings of the 10/66 Dementia Research Network (Shaji et al, 2003), older people in low- and middleincome countries are 'indivisible from their younger family members'. Despite larger households being associated with lower levels of carer strain, this was in fact as high as in high-income countries. Prince (2004) found that many family members had to cut back on work in order to care for an older individual with dementia.

The need to provide respite care for family members in the Indian context has been highlighted by Rao \& Shaji (2007). Collaborative care, through the use of support groups for carers that provide both information as well as outlets to vent pent up emotions, has become increasingly popular across countries. Group interventions that are educational and problem-focused and that discuss behavioural management have been found to be particularly useful (Haley, 1997) and they serve to delay nursing-home placement (Mittelman et al, 1996).
\end{abstract}

This article describes the development and pilot testing of a group intervention module for the carers of geriatric patients at a tertiary-care hospital in India. The work reported in this paper was conducted at a specialty out-patient geriatric clinic run once a week by the Department of Psychiatry at a tertiary centre, the National Institute of Mental Health and Neurosciences (NIMHANS), Bangalore. The catchment area comprises both urban and rural areas of four adjoining southern states of India (Karnataka, Andhra Pradesh, Tamil Nadu and Kerala) and the centre receives referrals from the rest of the country. The clinic team comprises four geriatric psychiatrists, four social workers, a neurologist and two psychologists. The clinic provides services for a heterogeneous geriatric population with diagnoses that include dementia, psychosis, mood disorders and other psychiatric disorders.

\section{Method}

The geriatric clinic team planned a regular group intervention programme for the carers of the patients who attend the clinic. Initially, three focus group discussions were held with 17 carers. 'Cue questions' on the recognition of symptoms, behavioural management, medical care and follow-up, use of support systems, carer burden and social welfare measures for senior citizens were used to facilitate these discussions. The findings from the focus groups and inputs from experts in the field of geriatric psychiatry were then used to prepare an intervention module. 
The module was divided into three sessions, with content as follows:

O session 1, psychoeducation on health problems related to old age

o session 2, psychosocial management of the aged person

o session 3, welfare measures available for the aged in India.

The module was then pilot-tested with 16 families, after which further changes were made. These changes included a shorter time span per session and simplifying the language. Group processes were then observed and recorded over 2 years of use of this module.

\section{Results}

\section{Characteristics of group sessions}

Each group session was conducted by at least two psychiatric social workers, working on rotation (these social workers were all members of the multidisciplinary team providing services at the geriatric clinic). The groups were heterogeneous in nature and comprised the carers of patients with varied neuropsychiatric diagnoses. Entry to and exit from the groups was open owing to the fluid nature of the outpatient department and the fact that families from outside the state of Karnataka were also accessing these services. Each session lasted 30-45 minutes and was repeated for 3 weeks, when it was followed by the next session (i.e. on a 3-weekly cycle). This pattern continued for 3 months, after which the whole intervention was repeated.

Up until December 2007, more than 65 group sessions had been conducted over the space of 2 years. On average, 8-10 family members attended the groups, which had a minimum of 4 and a maximum of 26 participants. The most common languages used were Kannada, Tamil, Hindi, Malayalam, Telugu and English. Sometimes more than one language was used, in which case translators helped. Of a total of 967 carers who attended the groups, 43\% were spouses, 35\% were adult children of the patient and $23 \%$ were 'other' (these included daughters-in-law, sons-in-law, and brothers/sisters, as well as a few friends, neighbours and other attendants).

\section{Group observations}

All the group sessions were helpful in allowing participants to share their experiences and burdens. The sessions helped carers to clarify their doubts and to learn new strategies of care; carers also had the benefit of being reassured that they were part of a large group who had experienced similar demands and stress. The researchers could elicit four main themes across all the group sessions (Table 1).
The specifically educational sessions ( 1 and 3 ) generated a number of questions among the carers. Of the three sessions, a higher degree of participation was found in session 2, when the group discussed the psychosocial management of aged persons. Compared with sessions 1 and 3, which adopted a psychoeducational methodology, session 2 was more of an interactional and experiential session. In this session, family members of patients with dementia often became very emotional and would cry while narrating their experiences. They were able to recollect the premorbid personality of the patient and this, they said, kept them going during times when the patient's symptoms were at their worst. Some family members were found to be extremely critical of their ill relative and expressed their anger at the degree of deterioration, even though they understood this to be caused by the disease. A few others who had been tending to an ill older relative for several years had a sense of resignation and seemed mildly depressed (sub-clinical). They spoke of their aged family members as a responsibility they recognised was theirs, and seemed to be resigned to their role as carers.

\section{Discussion}

Caring for a person with geriatric problems is very demanding. In order to develop any programmes to cater to the needs of carers in a cultural context, it is first essential to understand the needs, mental health issues and problems faced by carers with responsibility for an older person with psychiatric problems. In the group sessions, we found there were four main themes expressed by such carers (Table 1): emotional and cognitive responses; concerns about the patient's future; specific concerns of female spouses; and specific concerns of male spouses.

Carers expressed various emotional and cognitive responses to the care of a person with geriatric problems, such as anger, sadness, frustration, embarrassment, hypervigilance, acceptance, denial/disbelief, blame, criticality and curiosity. Stress often leads to problems with carers' mental and physical health (Ras \& Opala, 2001). Certain factors predict carer distress, such as behavioural problems in the patient, the nature of the carer's social support and their ability to cope with difficult situations (Ras \& Opala, 2001).

As most geriatric problems (notably dementia) are deteriorating conditions, carers had a number of queries about the patient's future, such as their ability to care for themselves (bathing, eating, grooming, personal hygiene), their ability to take on household responsibilities, their ability

Table 1 Emergent themes from the group process

\begin{tabular}{|c|c|c|c|}
\hline $\begin{array}{l}\text { Carer's emotional/cognitive } \\
\text { responses }\end{array}$ & $\begin{array}{l}\text { Carers' concerns about } \\
\text { the patient's future }\end{array}$ & Specific concerns of female spouses & Specific concerns of male spouses \\
\hline $\begin{array}{l}\text { - Anger } \\
\text { - Sadness } \\
\text { - Frustration } \\
\text { - Embarrassment } \\
\text { - Hypervigilance } \\
\text { - Acceptance } \\
\text { - Denial/disbelief } \\
\text { - Blame } \\
\text { - Criticality } \\
\text { - Curiosity }\end{array}$ & $\begin{array}{l}\text { - Ability to care for self } \\
\text { (bathing, eating, grooming, } \\
\text { personal hygiene) } \\
\text { - Ability to take on household } \\
\text { responsibilities } \\
\text { - Ability to socialise } \\
\text { - Patient's deteriorating } \\
\text { biological functioning (sleep, } \\
\text { appetite, bowel/bladder) }\end{array}$ & $\begin{array}{l}\text { - Burden of increased responsibility } \\
\text { - Difficulty understanding erratic } \\
\text { behaviour } \\
\text { - Loss of a breadwinner } \\
\text { - Loss of sense of protection and } \\
\text { security } \\
\text { - Increased dependence on adult } \\
\text { children and extended family } \\
\text { - Being blamed by society for } \\
\text { spouse's condition }\end{array}$ & $\begin{array}{l}\text { - Difficulties with household } \\
\text { chores } \\
\text { - Loss of routine } \\
\text { - Difficulty understanding } \\
\text { erratic behaviour } \\
\text { - Increased dependence on } \\
\text { adult children and extended } \\
\text { family }\end{array}$ \\
\hline
\end{tabular}


to socialise with the extended family and the wider community and, finally, how to cope with their deteriorating biological functioning (sleep, appetite, bowel/bladder). As the burden of caring directly correlates with the level of independent functioning of the patient (Ryden, 1998), it was understandable that the carers were worried about the future ability of patients to care for themselves.

Gender sensitivity is required in understanding carers' problems in dealing with an ill relative. We found that male and female carers had different requirements and concerns in caring for a spouse with geriatric problems. The specific concerns of female spouses centred on the burden of increased responsibility, the difficulty in understanding erratic behaviour, the loss of the family's breadwinner, a loss of sense of protection and security, their increased dependence on adult children and the extended family, and being blamed by society for their spouse's condition. The specific concerns of male spouses who were carers included difficulties with household chores, a loss of routine, difficulty understanding erratic behaviour and increased dependence on adult children and the extended family. Among the wider group of carers, the needs of children of patients differ from those who are spouses. Programmes should be developed to address different needs, depending upon the gender of the carer and the relationship to the patient.

The results need to be understood in the light of certain limitations to the study, such as the short duration of the group sessions (30-45 minutes, due to limited resources and lack of infrastructure). Further, as it was an open group session for out-patient carers, the group composition varied, and not all carers were able to attend all three group sessions.

In conclusion, the geriatric group programme was acceptable to the carers of out-patients with geriatric ailments. Further development and distribution of group intervention materials, such as handouts on the various topics discussed, could be helpful for carers. Future programmes need to deal with gender-specific issues in taking care of patients with geriatric disorders before the efficacy of these group sessions is tested in a larger, controlled intervention study.

\section{Memoriam}

The primary researcher in this study, Dr Udaya Kumar GS, passed away in June 2007. The authors dedicate this paper to him.

\section{References}

Ferri, C. P., Prince, M., Brayne, C., et al (2005) Global prevalence of dementia: a Delphi consensus study. Lancet, 366, 2112-2117.

Haley, W. E. (1997) The family caregiver's role in Alzheimer's disease. Neurology, 48 (suppl. 6), S25-S29.

International Institute of Ageing (2001) Health Status of Elderly in India (BOLD quarterly gerontological publication). United Nations.

Mittelman, M. S., Ferris, S. H., Shulman, E., et al (1996) A family intervention to delay nursing home placement of patients with Alzheimer's disease: a randomized controlled trial. JAMA, 276, 1725-1731.

Prince, M. (2004) 10/66 Dementia Research Group. Care arrangements for people with dementia in developing countries. International Journal of Geriatric Psychiatry, 19, 170-177.

Rao, T. S. S. \& Shaji, K. S. (2007) Demographic aging: implications for mental health. Indian Journal of Psychiatry, 49, 78-80.

Ras, P. \& Opala, G. (2001) Obciazenie opiekunów osób z otepieniem. [Burden of caregivers caring for persons with dementia.] Wiadomosci Lekarskie, 54, 94-100. (Polish article with English abstract.)

Ryden, M. B. (1998) A theory of caring and dementia. American Journal of Alzheimer's Disease and Other Dementias, 13, 203-207.

Shaji, K. S., Smitha, K., Lal, K. P., et al (2003) Caregivers of people with Alzheimer's disease: a qualitative study from the Indian 10/66 Dementia Research Network. International Journal of Geriatric Psychiatry, 18, 1-6.

\title{
Twenty-five years of expectation: where are the services for older people with mental illness in Africa?
}

\author{
Thomas Clausen ${ }^{1}$ and Adrian O. Wilson²
}

1Norwegian Centre for Addiction Research (SERAF), University of Oslo, Norway, email thomas.clausen@medisin.uio.no ${ }^{2}$ African Foundation for Research and Interdisciplinary Training in Ageing, Harare, Zimbabwe

$\mathrm{M}$ ental health disorders account for about $14 \%$ of the global burden of disease. Neuropsychiatric disorders may be responsible for more than 1.2 million deaths annually (Prince et al, 2007). Around $80 \%$ of those affected live in low- and middle-income countries. Yet, despite the fact that older persons carry a disproportionate burden of non-communicable disease and mental disorder, they are not seen as priority issues for healthcare provision in these countries. Logically and ethically, older persons should be prioritised for targeted interventions, alongside the generic strengthening of primary and community health provision. African governments, spurred on by the specific agendas of non-governmental and parastatal organisations, continue with more urgent tasks; their healthcare provision is oriented towards the 'younger generations' (maternal and child healthcare, and infection). In most African countries, the expenditure specifically targeted for mental health is below $1 \%$ of the total healthcare budget, that is, effectively non-existent (Saxena et al, 2007). 